\title{
Desempenho termo-hidráulico de nanofluidos compostos por nanotubos de carbono de paredes múltiplas funcionalizados (MWCNT-OH/água)
}

\author{
Thermo-hydraulic performance of nanofluids composed of functionalized multiple-walled carbon \\ nanotubes (MWCNT-OH/water) \\ Rendimiento termohidráulico de nanofluidos compuestos de nanotubos de carbono de paredes \\ múltiples funcionalizados (MWCNT-OH/agua)
}

\author{
Alexandre Melo de Oliveira \\ ORCID: https://orcid.org/0000-0002-8298-3543 \\ Instituto Federal de Ciência e Tecnologia de São Paulo, Brasil \\ E-mail: alexandre.melo@ifsp.edu.br \\ Lindomar Matias Gonçalves \\ ORCID: https://orcid.org/0000-0001-9377-4395 \\ Universidade Federal de Itajubá, Brasil \\ E-mail: lindomar@unifei.edu.br \\ Amir Zacarias Mesquita \\ ORCID: https://orcid.org/0000-0003-3411-5984 \\ Centro de Desenvolvimento da Tecnologia Nuclear, Brasil \\ E-mail: amir@cdtn.br \\ Ênio Pedone Bandarra Filho \\ ORCID: https://orcid.org/0000-0003-4586-3857 \\ Universidade Federal de Uberlândia, Brasil \\ E-mail: bandarra@ufu.br \\ André Guimarães Ferreira \\ ORCID: https://orcid.org/0000-0002-0694-5369 \\ Centro Federal de Educação Tecnológica de Minas Gerais, Brasil \\ E-mail: agferreira@cefetmg.br
}

\begin{abstract}
Resumo
Com objetivo de avaliar a potencialidade de um novo fluido capaz de melhorar a eficiência dos processos de troca térmica nos sistemas de refrigeração, o presente trabalho propôs o estudo do desempenho termo-hidráulico de nanofluidos constituídos por nanopartículas de nanotubos de carbono do tipo MWCNT dispersos em água destilada. Foram utilizadas nanopartículas com grau de funcionalização - $\mathrm{OH}, 3 \%, 6 \%$ e $9 \%$ para produzir nove amostras de nanofluidos. Foi utilizado o método de "dois passos", com auxílio de sonicação e homogeneização de alta pressão, para dispersar as nanopartículas no fluido base. Para a avaliação do desempenho termo-hidráulico foram realizadas as seguintes etapas: produção dos nanofluidos pelo método de dois passos. A utilização da bancada experimental permitiu obter os parâmetros necessários para a determinação do coeficiente de transferência de calor por convecção e desempenho termo-hidráulico.
\end{abstract}

Palavras-chave: Nanotecnologia; Nanotubos; Desempenho termo-hidráulico; Nanopartículas.

\begin{abstract}
In order to evaluate the potential of a new fluid capable of improving the efficiency of thermal exchange processes in refrigeration systems, the present work proposed the study of the thermo-hydraulic performance of nanofluids constituted by nanoparticles of carbon nanotubes of the type MWCNT dispersed in distilled water. Nanoparticles with -OH functionalization degree, $3 \%, 6 \%$ and $9 \%$ were used to produce nine samples of nanofluids. The "two-step" method, with the help of sonication and high-pressure homogenization, was used to disperse the nanoparticles in the base fluid. To evaluate the thermo-hydraulic performance, the following steps were performed: production of the nanofluids by the two-step method. The use of the experimental bench allowed to obtain the necessary parameters for the determination of the heat transfer coefficient by convection and thermohydraulic performance.
\end{abstract}

Keywords: Nanotechnology; Nanotubes; Thermo-hydraulic performance; Nanoparticles.

\section{Resumen}

Con el objetivo de evaluar el potencial de un nuevo fluido capaz de reducir eficientemente dos procesos de intercambio térmico en nuestros sistemas de enfriamiento, presentamos un trabajo sobre el desempeño termo hidráulico de nano fluidos constituidos por nano partículas de nanotubos de carbono del tipo MWCNT dispersos en agua destilada. Se 
utilizaron nano partículas con un grado de funcionalización -OH, 3\%, 6\% y 9\% para producir nueve muestras de nano fluidos. Se utilizó el método de “dos pasos”, con la ayuda de la sonicación y la homogeneización a alta presión, para dispersar las nanas partículas en el fluido base. Se tomaron los siguientes pasos para evaluar el desempeño termo hidráulico: producción de los nanos fluidos por el método de dos pasos. El uso del banco experimental permitió obtener los parámetros necesarios para la determinación del coeficiente de transferencia de calor por convección y rendimiento termo hidráulico.

Palabras clave: Nanotecnología; Nanotubos; Rendimiento termo hidráulico; Nano partículas.

\section{Introdução}

Nanofluidos são constituídos por dispersões coloidais com um refrigerante tradicional como uma base na qual as nanopartículas são suspensas. O conceito “nanofluido” foi desenvolvido, em 1995, por Choi (1995), como sendo uma nova classe de fluidos composta por fluidos que contém nanopartículas dispersas em fluidos tradicionalmente utilizados em trocadores de calor como água, etilenoglicol e óleo térmico. Desenvolvimentos subsequentes em engenharia de nanofluidos contribuíram para o rápido crescimento da nanotecnologia e de tecnologias de superfície ao longo da última década (Chupin et al., 2008).

Muito tem se pesquisado sobre a concepção de novos fluidos capazes de melhor a taxa de transferência de calor. Com sistemas de potência de escalas cada vez menores, faz-se necessário o desenvolvimento de sistemas energéticos mais eficientes. De acordo com o site Science Direct (2020), o número de publicações, artigos e patentes, de periódicos relacionados com nanofluidos vem crescendo na última década, conforme pode ser observado na Figura 1. Estima-se que mais de 300 grupos de pesquisa e empresas estão envolvidas com investigação em nanofluidos a nível mundial. Além disso, vários artigos de revisão sobre transferência de calor em nanofluidos foram publicados.

O estudo de novos fluidos que melhorem a taxa de remoção de calor é fundamental para se obter maior eficiência de sistemas energéticos. Dentre os diversos fatores que comprometem a eficiência dos sistemas energéticos, podem-se destacar as limitações termofísicas dos fluidos convencionais, inibindo de forma bastante significativa algumas aplicações industriais. Neste trabalho, pretende-se melhorar as características de transferência de calor de fluidos comumente utilizados, através da adição de nanopartículas, constituídas de nanotubos de carbono, em água, que é o fluido mais utilizados para refrigeração de sistemas industriais, notadamente, reatores nucleares.

Figura 1 - Publicações relacionadas com nanofluidos.

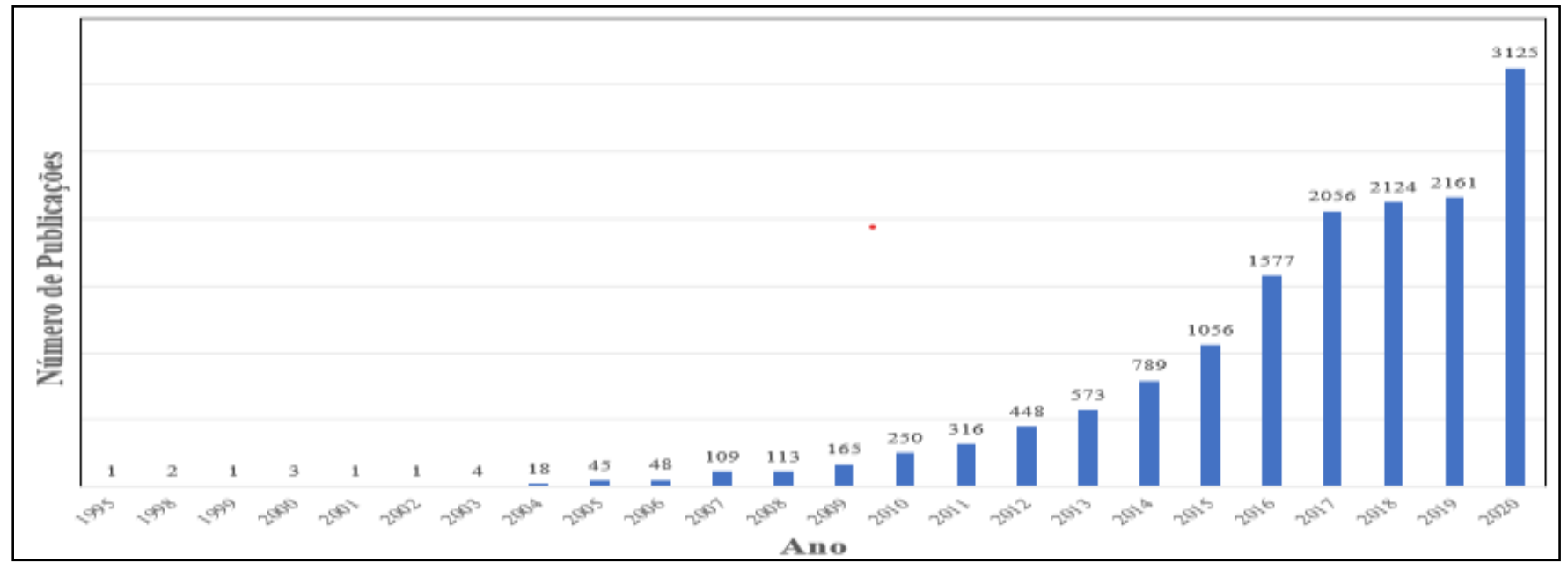

Fonte: Science Direct (2020). 


\subsection{Objetivos e perguntas da pesquisa}

O presente trabalho tem como objetivo principal estudar o comportamento térmico e hidráulico de nanofluidos de MWCNT/ $\mathrm{H}_{2} \mathrm{O}$ com diferentes concentrações em massa de nanopartículas e determinar, experimentalmente, seu coeficiente convectivo e a perda de carga para escoamento monofásico em tubo circular reto e horizontal em regime turbulento.

\section{Materiais e Métodos}

A pesquisa desenvolvida pode ser classificada como sendo de natureza quantitativa, de acordo de acordo com a definição dos tipos de pesquisa proposto por Pereira et al. (2018).

A avaliação do desempenho termo-hidráulico foi realizada de acordo com as seguintes etapas:

- Produção amostras de nanofluidos estáveis com concentrações volumétricas igual a 0,005\%; 0,01\% e 0,05\%, para cada tipo de nanopartícula;

- Determinação experimental das propriedades térmicas dos nanofluidos (condutividade, viscosidade e massa específica);

- Teste de escoamento interno dos nanofluidos produzidos, em tubo circular reto e horizontal, envolvendo uma ampla faixa de condições experimentais.

Na preparação de nanofluidos utilizando a técnica de passo único, a nanopartícula é produzida e, simultaneamente, dispersa no fluido base. A técnica de duas etapas ou "dois passos", tem início com nanopartículas produzidas em forma de pó e dispersas em um fluido base. É importante ressaltar que esta técnica requer o emprego de energia externa, como ultrassonicação ou homogeneização por alta pressão, com o objetivo de eliminar os aglomerados de nanopartículas e obter um nanofluido com partículas dispersas de forma mais homogênea e com mais estabilidade da dispersão.

O método de dois passos apresenta um custo menor em relação ao método de passo único, além de ser um método mais versátil, possibilitando produzir diversos tipos de nanofluidos com um mesmo tipo de nanopartícula, apenas se alterando o fluido base a ser utilizado.

A síntese dos nanofluidos foi realizada pelo método de "dois passos", utilizando-se os seguintes procedimentos: vibração ultrassônica e/ou homogeneização de alta pressão. Em seguida, as nanopartículas foram adicionadas ao fluido base (água) e submetidas à sonicação e ao homogeneizador a alta pressão para obtenção do nanofluido. Um esquema mostrando a etapa de dispersão e obtenção do nanofluido final pode ser observado na Figura 2.

Figura 2 - Esquema da síntese de nanofluidos.

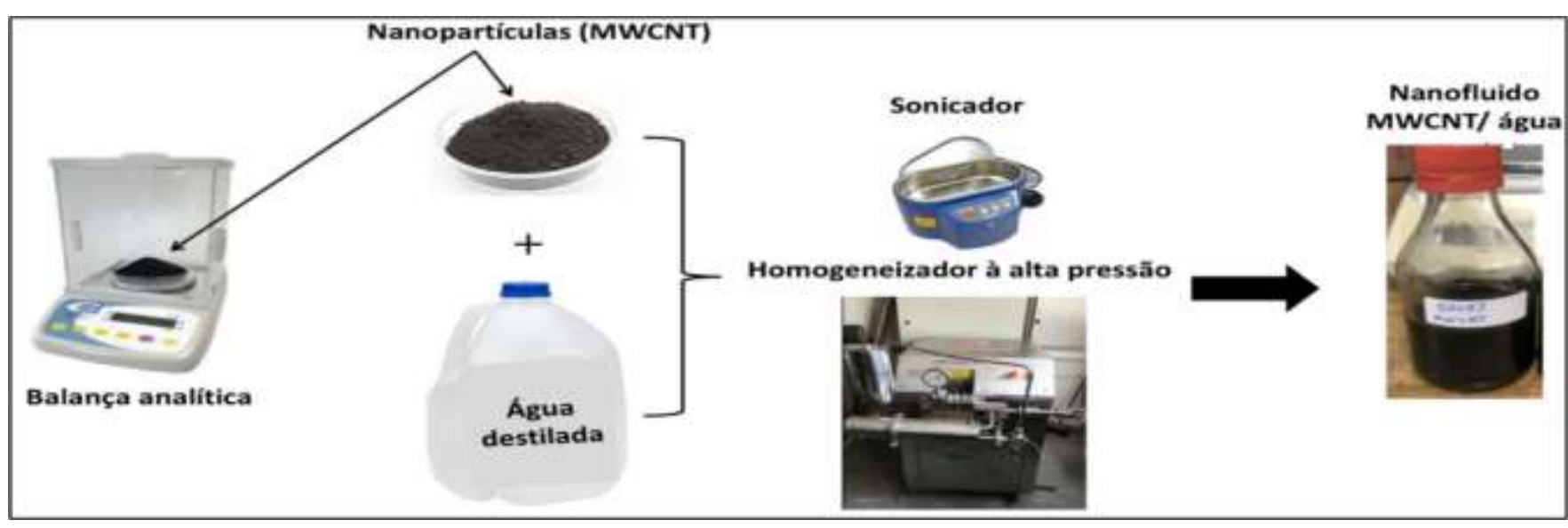

Fonte: Autores. 
O homogeneizador de alta pressão é um equipamento no qual a mistura é pressurizada, por meio de pistões e depois esse fluido é direcionado a uma câmara de interação. Na câmara de interação, a combinação de elevadas taxas de cisalhamento, da energia de cavitação induzida por elevados gradientes de pressão e dos impactos da mistura com a parede, são responsáveis pela quebra de aglomerações de nanopartículas, deixando-as dispersas de forma estável e homogêneas no fluido base. As amostras foram dispersas em água destilada com as seguintes concentrações volumétricas iguais a $0,001 \%, 0,05 \%$ e $0,1 \%$.

Na Tabela 1 são apresentadas as características das nanopartículas utilizadas neste trabalho.

Para avaliar o desempenho termo-hidráulico de nanofluidos de MWCNT/água, foi idealizado e adaptado um circuito que possibilitasse determinar a perda de carga e o coeficiente de transferência de calor com o nanofluido escoando em regime laminar e/ou turbulento. As dimensões da bancada experimental podem ser observadas na Figura 3. O equipamento experimental utilizado está localizado no Laboratório de Energia, Sistemas Térmicos e Nanotecnologia (LEST-Nano) da Universidade Federal de Uberlândia (UFU). Ele já foi utilizado em diversos estudos anteriores envolvendo nanofluidos. Portanto, é capaz de atender as condições térmicas de fluidodinâmicas necessárias para a solução experimental do presente trabalho.

Tabela 1 - Características dos nanofluidos produzidos utilizados no presente trabalho.

\begin{tabular}{|c|c|c|c|c|c|c|c|}
\hline $\begin{array}{c}\text { A breviação } \\
\text { M1C1 }\end{array}$ & $\begin{array}{c}\text { Tipo de } \\
\text { nanoparticula }\end{array}$ & $\begin{array}{c}-\mathrm{OH} \\
{[\mathrm{wt} \%]}\end{array}$ & $\begin{array}{c}\text { Fluido } \\
\text { base }\end{array}$ & $\mathrm{L}[\mu \mathrm{m}]$ & $d[\mathrm{~nm}]$ & $\mathrm{r}=\mathrm{L} / \mathrm{d}$ & $\begin{array}{c}\text { Concentração } \\
\text { volumetrica } \\
\varphi \text { final }[\%] \\
0,005\end{array}$ \\
\hline $\mathrm{M}_{1} \mathrm{C}_{2}$ & MWCNT & $4 \%$ & Agua & $10-30$ & $10-30$ & 1000 & 0,01 \\
\hline $\mathrm{M}_{103}$ & & & & & & & 0,05 \\
\hline $\mathrm{M}_{2} \mathrm{C}_{1}$ & & & & & & & 0,005 \\
\hline $\mathrm{M}_{2} \mathrm{Cl}_{2}$ & MWCNT & $6 \%$ & Agua & $10-30$ & $20-40$ & 667 & 0,01 \\
\hline $\mathrm{M} 2 \mathrm{Cl}_{3}$ & & & & & & & 0,05 \\
\hline $\mathrm{M} 3 \mathrm{C}_{1}$ & & & & & & & 0,005 \\
\hline $\mathrm{M}_{3} \mathrm{C}_{2}$ & MWCNT & $9 \%$ & Água & $10-20$ & $50-80$ & 231 & 0,01 \\
\hline $\mathrm{M} 3 \mathrm{C} 3$ & & & & & & & 0,05 \\
\hline
\end{tabular}

Fonte: Autores.

Figura 3 - Bancada experimental e suas dimensões principais.

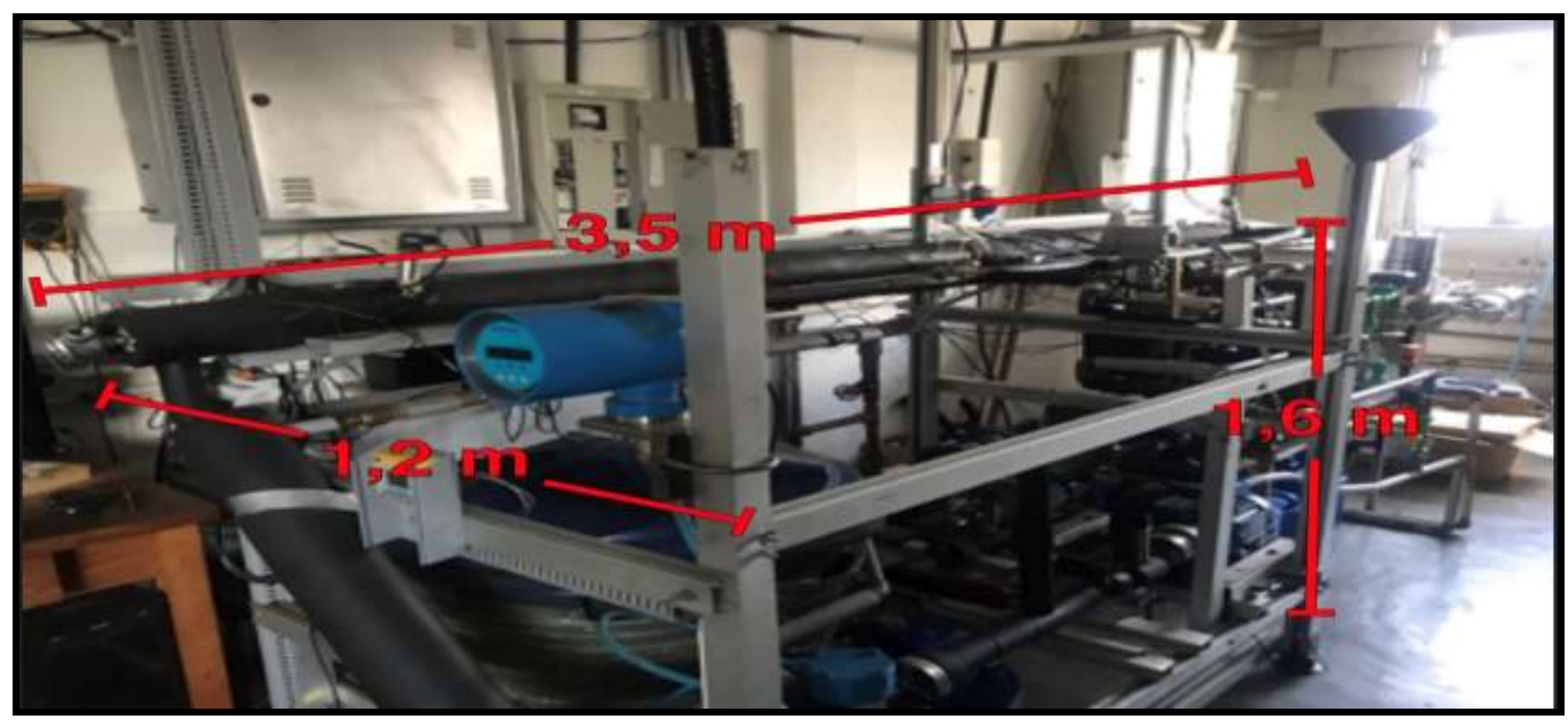

Fonte: Autores. 
Na Figura 4 é apresentado o diagrama esquemático da bancada experimental do LEST-Nano da UFU, mostrando seus principais equipamentos, como a seção de testes, o circuito de pré-aquecimento, o trocador de calor do circuito de resfriamento, o reservatório e a bomba com acoplamento magnético.

Figura 4 - Diagrama esquemático da bancada experimental.

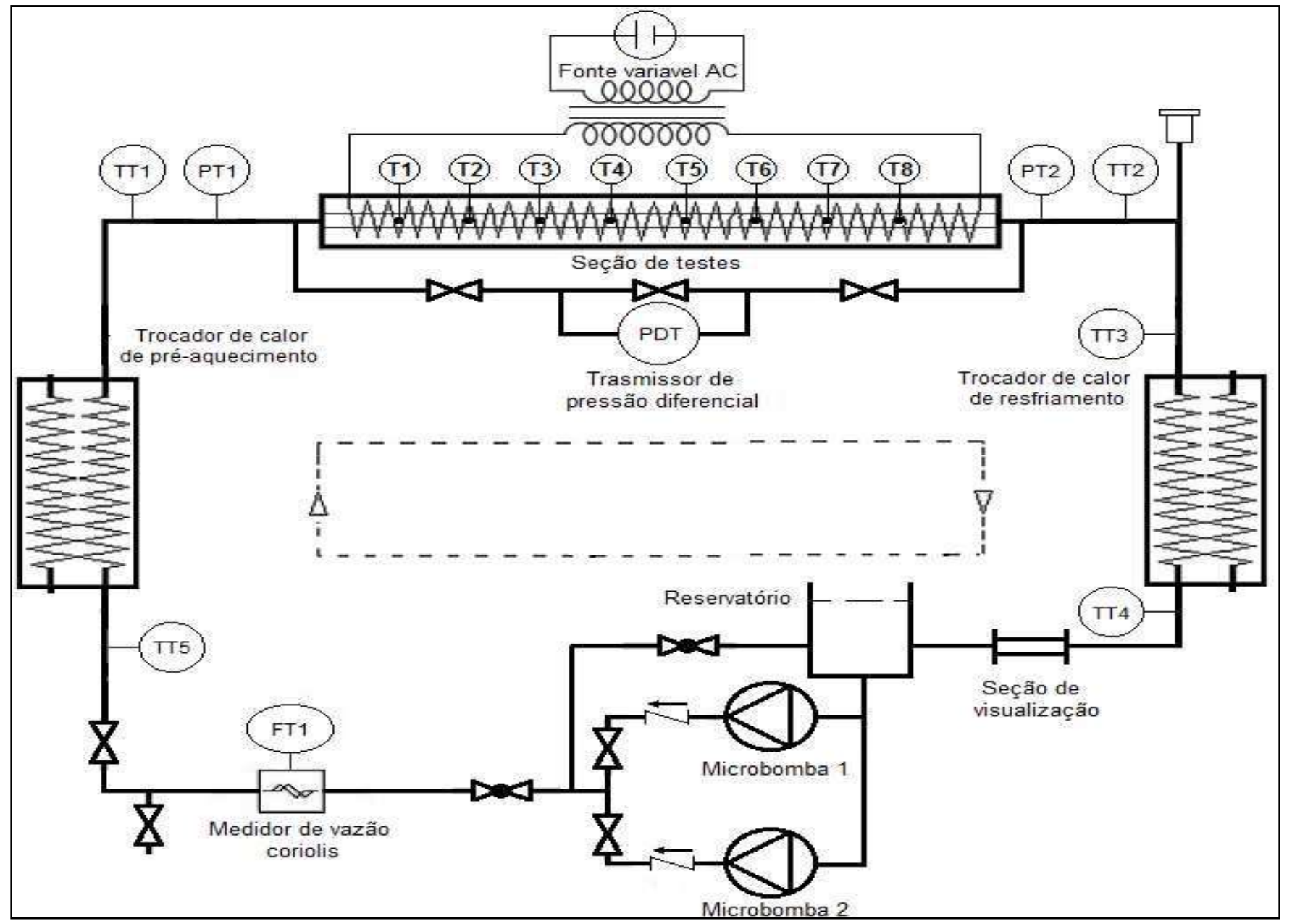

Fonte: Autores.

O sistema de monitoramento, medição e aquisição de dados necessários para avaliar o desempenho termo-hidráulico dos nanofluidos, é controlado pela interface homem-máquina marca LabVIEW ${ }^{\circledR}$, que possibilita a comunicação entre os equipamentos e o operador que monitora o processo. É a partir desta interface (Figura 5) que as informações são enviadas ou recebidas dos instrumentos instalados na bancada experimental. Desta forma, além de efetuar a aquisição dos dados, o operador pode ajustar parâmetros para estabelecer as condições nominais dos testes, bem como solucionar eventuais anomalias que podem ocorrer durante sua execução. O sistema de monitoramento e aquisição de dados, projetado e implementado na bancada experimental é fundamentado na norma de simbologia gráfica para visualização de processos Graphic Symbols for Process Displays (ISA,1985). 
Figura 5 - Tela principal de controle e monitoramento da interface gráfica no programa LabVIEW ${ }^{\circledR}$.

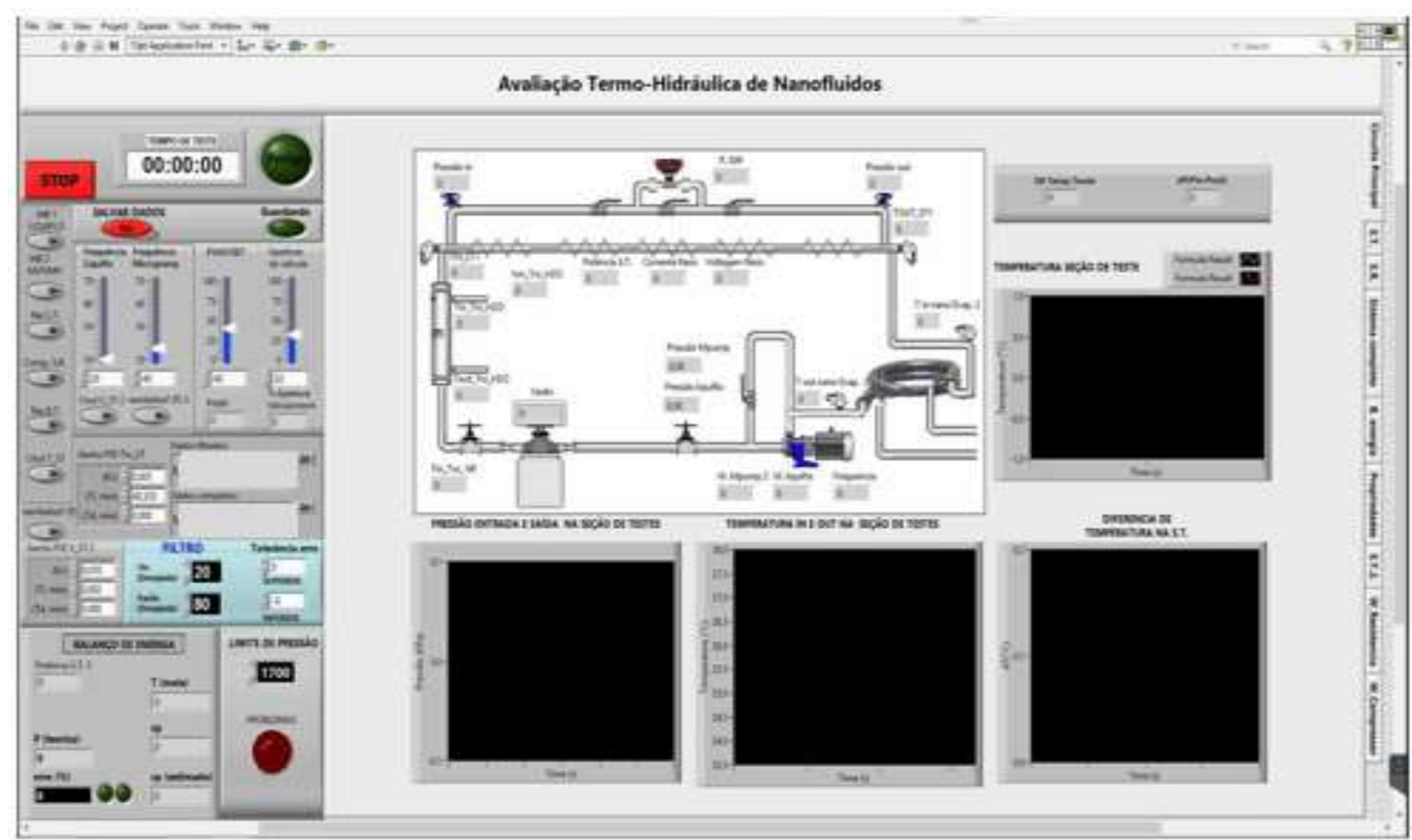

Fonte: Autores.

Cada fluido foi submetido a um fluxo de calor Q" $\approx 20 \mathrm{~kW} / \mathrm{m}^{2}$, em regime turbulento com número de Reynolds variando entre 10000 e 20000 , temperatura de entrada igual a Tent $=(35,0 \pm 0,2)^{\circ} \mathrm{C}$, com vazão mássica, $\mathrm{m}$; variando de $0,04 \mathrm{a} 0,07 \mathrm{~kg} / \mathrm{s}$, com intervalos de $0,01 \mathrm{~kg} / \mathrm{s}$. Assim, para cada fluido, foram realizados 4 (quatro) experimentos, sendo 9 (nove) com as amostras de nanofluidos e 1 (um) experimento com a amostra do fluido base (água destilada), conforme Tabela 2. Portanto, totalizando 40 experimentos.

Tabela 2 - Valores nominais das condições operacionais de ensaio.

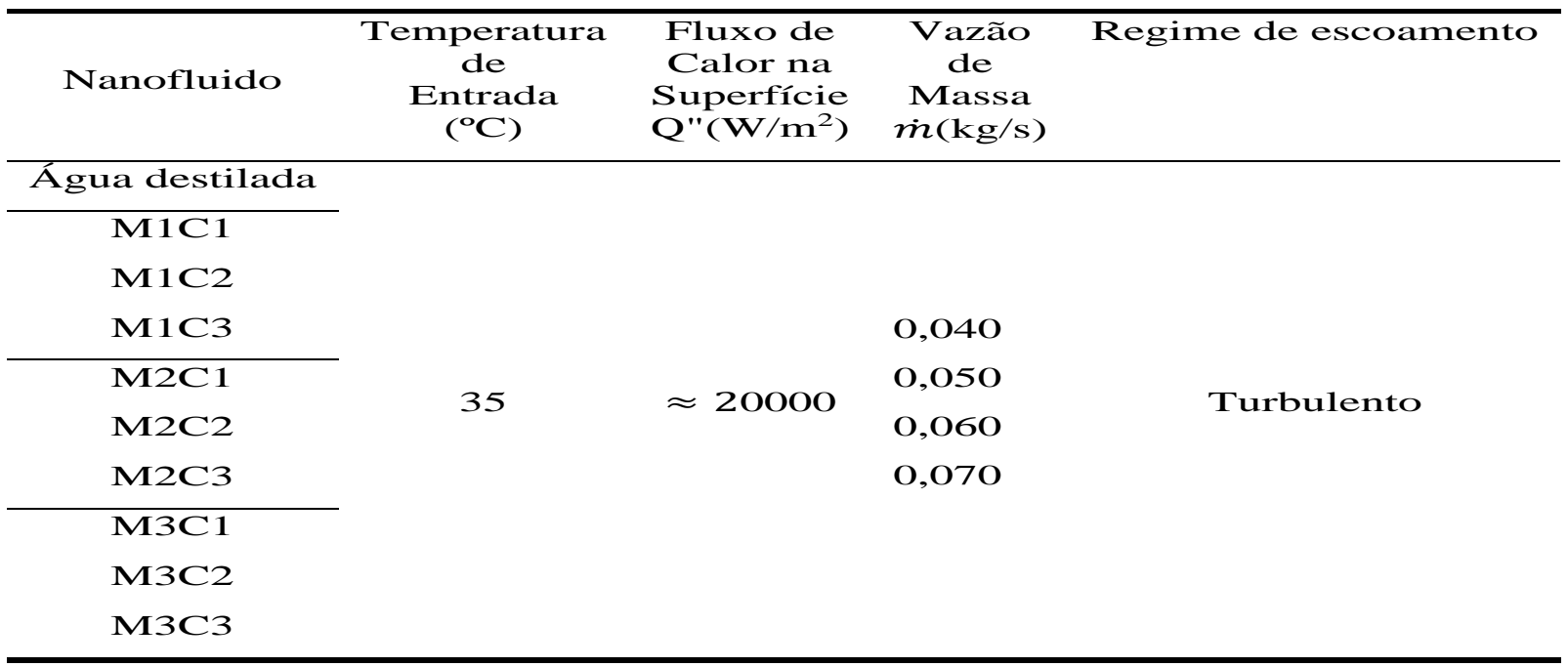

Fonte: Autores. 


\subsection{Balanço de energia para determinação do coeficiente de transferência de calor}

Como o escoamento em tubo é confinado, um balanço de energia pode ser utilizado para determinar como a temperatura média $\operatorname{Tm}(\mathrm{x})$ varia ao longo do tubo e como a transferência de calor total está relacionada com a diferença de temperatura na entrada e na saída do tubo. Considere o volume de controle para escoamento interno em um tubo (Figura 6) a seguir:

Figura 6 - Volume de controle para escoamento interno em um tubo.

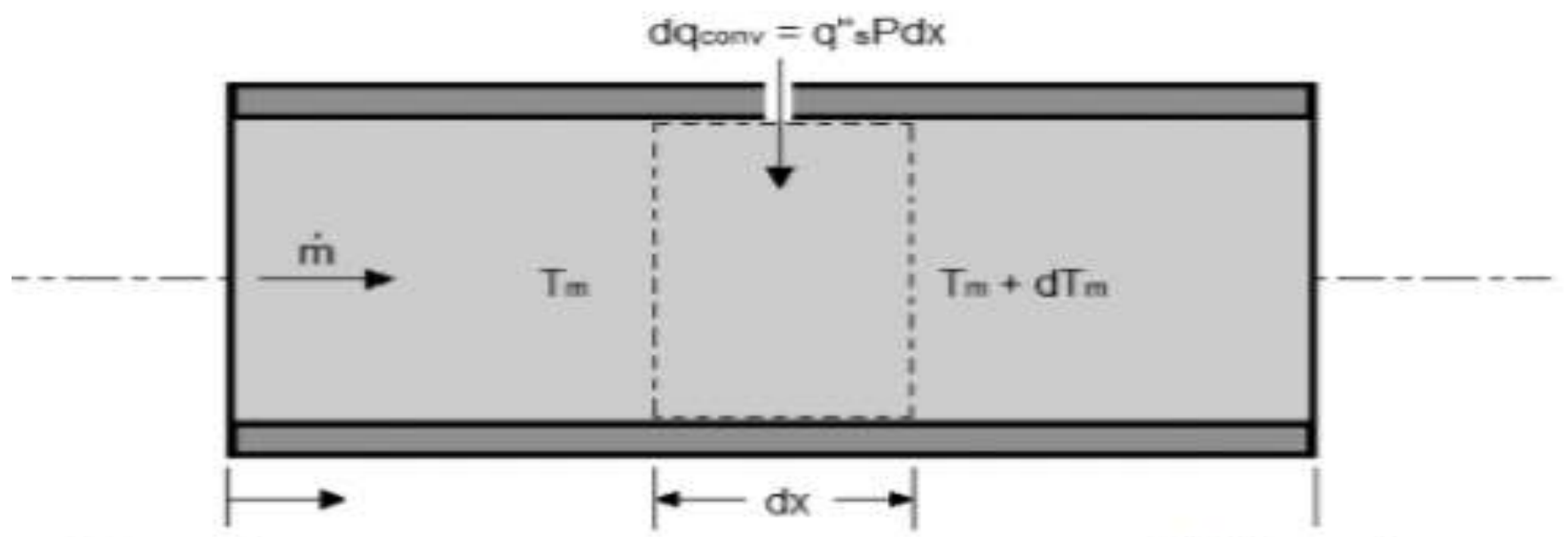

Entrada, ent

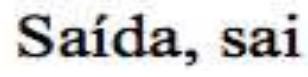

Fonte: Incropera, DeWitt, Bergman, \& Lavine, (2015).

Considerando que a vazão mássica $\dot{m}$ é constante e que a transferência de calor por convecção ocorre na superfície interna, aplicando o princípio da conservação da energia para o escoamento do fluido em regime estacionário no interior de tubos, é possível obter a Equação 1:

$$
q_{\text {conv }}=\dot{m} c_{p}\left(T_{m, s a i}-T_{m, e n t}\right)
$$

Onde $T_{m, s a i}$ e $T_{m, e n t}$ é a diferença entre a temperaturas médias na saída e na entrada da seção de testes, $\mathrm{c}_{\mathrm{p}}$ é o calor específico a pressão constante e $\dot{m}$ é a vazão mássica.

A Equação 2 é uma expressão geral que se aplica independentemente da natureza das condições térmicas na superfície e no escoamento do tubo.

A lei de resfriamento de Newton (Equação 2) permite determinar o coeficiente local de transferência de calor por convecção (h), sendo descrita por:

$$
q_{s} "=h\left(T_{s} T_{m}\right)
$$

Onde q" é o fluxo de calor constante na superfície, $\mathrm{T}_{\mathrm{s}}$ é a temperatura registrada pelo termopar na parede do tubo da seção de testes e $\mathrm{T}_{\mathrm{m}}$ é a temperatura média.

A temperatura média é definida de maneira que o termo $\dot{m} c_{p} T_{m}$ represente a taxa real de advecção de energia térmica (ou entalpia), integrada na seção transversal, obtendo-se:

$$
d q_{\text {conv }}=\dot{m} c_{p}\left[\left(T_{m}+d T_{m}\right)-T_{m}\right]
$$

$\mathrm{Ou}$, 


$$
d q_{\text {conv }}=\dot{m} c_{p} d T_{m}
$$

Representando a taxa de calor para o elemento diferencial por $d q_{c o n v}=q " P d x$ onde P é o perímetro do tubo $(P=\pi D)$. Substituindo na Equação 4, tem-se que:

$$
\frac{d T_{m}}{d x}=\frac{q_{s} " P}{\dot{m} c_{p}}=\frac{P}{\dot{m} c_{p}} h\left(T_{s}-T_{m}\right)
$$

Para um fluxo térmico constante na superfície, a taxa de transferência de calor total é dada por:

$$
q_{\text {conv }}=q_{s} "(P L)
$$

Como o produto $P L$ é a área interna $A_{\text {int }}$ do tubo, tem-se que:

$$
q_{\text {conv }}=q_{s} " A_{\text {int }}
$$

Para $q_{\mathrm{s}}$ " constante a expressão central da Equação 7 é uma constante que independe de x. Integrando-se esta expressão desde $\mathrm{x}=0$, tem-se que:

$$
\int_{x=0}^{x} \frac{d T_{m}}{d x}=\int_{x=0}^{x} \frac{q_{s} " P}{\dot{m} c_{p}}
$$

Logo,

$$
T_{m}(x)=T_{m, e n t}+\frac{q^{n} \cdot \pi \cdot D \cdot x}{\dot{m} \cdot c_{P}}
$$

O coeficiente convectivo local $h(x)$ é obtido pela Equação 10, já o fluxo de calor $q_{\mathrm{s}}$ " é determinado pela razão entre a potência elétrica $P_{\text {ele }}=V I$ e área interna $A_{\text {int }}$ do tubo. Portanto:

$$
\begin{gathered}
h(x)=\frac{q^{\prime \prime}}{T_{P}(x)-T_{m}(x)} \\
\mathrm{q}^{\prime \prime}=\frac{\mathrm{P}_{\text {ele }}}{\mathrm{A}_{\text {int }}}=\frac{\mathrm{V} \cdot \mathrm{I}}{\pi \cdot \mathrm{D} \cdot \mathrm{L}}
\end{gathered}
$$

Todos os resultados obtidos para o coeficiente convectivo, foram comparados com o fluido base (água destilada). Também serão apresentadas as comparações da perda de carga e fator de atrito entre as amostras de nanofluidos e o fluido base. Finalmente, será apresentada uma avaliação do desempenho termo-hidráulico das amostras de nanofluidos testadas.

Em geral os nanofluidos apresentam um coeficiente de transferência de calor mais elevado do que o do fluido base. Entretanto, isto não determina obrigatoriamente que o nanofluido melhore o desempenho do sistema térmico, visto que, frequentemente, na literatura, o coeficiente convectivo em relação ao fluido base é avaliado levando-se em consideração um mesmo número de Reynolds. Atualmente, autores como (Sadeghinezhad et al., 2014); (Utomo et al., 2014) e (Kazi, Duffy, \& Chen, 2014) consideram a comparação do coeficiente de transferência de calor na mesma velocidade de fluxo (potência de bombeamento). Tal comparação se mostra mais apropriada quando se trata de nanofluidos, pois fazer a comparação de coeficientes de transferência de calor para dois fluidos diferentes, com o mesmo número de Reynolds demanda maior velocidade de fluxo para o fluido com viscosidade mais elevada. Deste modo, a maior transferência de calor no mesmo número de Reynolds, pode não apenas ser devido ao desempenho do nanofluido, mas pode ser originada por uma mais elevada taxa de fluxo aplicada ao nanofluido. Nessa perspectiva, os autores citados sugerem a potência de bombeamento como método de comparação, visto que são consideradas tanto a transferência de calor como a perda de carga do nanofluido. 
Por esses motivos, os resultados do coeficiente de transferência de calor serão apesentados em função do número de Reynolds $(\operatorname{Re})$ e também da velocidade mássica $(G)$, representada pela Equação 12, que é um parâmetro importante para a perda de carga.

$$
G=\frac{4 \dot{m}}{\pi D^{2}}
$$

Onde $\dot{m}$ representa a vazão mássica e $D$ é o diâmetro interno da tubulação.

O desempenho termo-hidráulico do nanofluido é determinado levando em conta a relação entre o coeficiente convectivo e a potência de bombeamento. Os valores experimentais da potência de bombeamento, $\dot{W}_{B}$, obtidos pela Equação 13, levam em consideração a perda de carga, $\Delta P$, medida na seção de teste para cada vazão mássica $\dot{m}$.

$$
\dot{W}_{B}=\frac{\dot{m} \Delta P}{\rho}
$$

Onde $\rho$ representa a massa específica do fluido em determinada condição de operação.

\section{Resultados}

\subsection{Coeficiente convectivo}

Os resultados experimentais para o coeficiente convectivo, $h\left[\mathrm{~W} / \mathrm{m}^{2} \mathrm{~K}\right]$, das amostras dos nanofluidos MWCNT(-

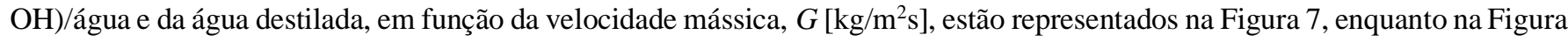
8 são apresentados os mesmos resultados em função do número de Reynolds (Re).

$\mathrm{Na}$ amostra de nanofluido com menor grau de funcionalização (Figura 7a), os incrementos no coeficiente convectivo de transferência de calor foram, em média, de $-0,4 \%,-0,5 \%$ e 1,0\%, para as amostras M1C1, M1C2 e M1C3, respectivamente. O maior incremento obtido para o coeficiente convectivo de transferência de calor foi de 1,5\% para a amostra M1C3 na velocidade mássica igual a $1578,6 \mathrm{~kg} / \mathrm{m}^{2} \mathrm{~s}$.

$\mathrm{Na}$ amostra com grau de funcionalização intermediário (Figura 7b) os incrementos no coeficiente convectivo de transferência de calor foram, em média, de 1,2\%, 3,8\% e 1,1\%, para as amostras $\mathrm{M} 2 \mathrm{C} 1, \mathrm{M} 2 \mathrm{C} 2$ e $\mathrm{M} 2 \mathrm{C} 3$, respectivamente. O maior incremento obtido para o coeficiente convectivo de transferência de calor foi de 4,2\% para a amostra M2C2 na velocidade mássica igual a $1578,6 \mathrm{~kg} / \mathrm{m}^{2} \mathrm{~s}$.

$\mathrm{Na}$ amostra com grau de funcionalização mais elevado (Figura 7c), os incrementos no coeficiente convectivo de transferência de calor foram, em média, de, 3,5\%, 4,5\% e 1,5\%, para as amostras $\mathrm{M} 3 \mathrm{C} 1, \mathrm{M} 3 \mathrm{C} 2$ e M3C3, respectivamente. O maior incremento obtido para o coeficiente convectivo de transferência de calor foi de 5,4\% para a amostra $\mathrm{M} 3 \mathrm{C} 2$ na velocidade mássica igual a $1894,5 \mathrm{~kg} / \mathrm{m}^{2} \mathrm{~s}$.

Resumidamente, nas amostras de nanofluidos (M2C1, M2C2, M2C3, M3C1, M3C2 e M3C3), pode ser observado um possível efeito da adição de nanopartícula no aumento do coeficiente de transferência de calor em regime turbulento. No entanto, as amostras de nanofluidos $\mathrm{M} 3 \mathrm{C} 1, \mathrm{M} 3 \mathrm{C} 2$ e $\mathrm{M} 3 \mathrm{C} 3$ apresentaram os maiores incrementos no coeficiente de transferência de calor, quando comparados com os incrementos observados nas amostras $\mathrm{M} 2 \mathrm{C} 1, \mathrm{M} 2 \mathrm{C} 2$ e M2C3, na mesma concentração de nanopartículas. 
Figura 7 - Coeficiente convectivo em função da velocidade mássica $(G)$.

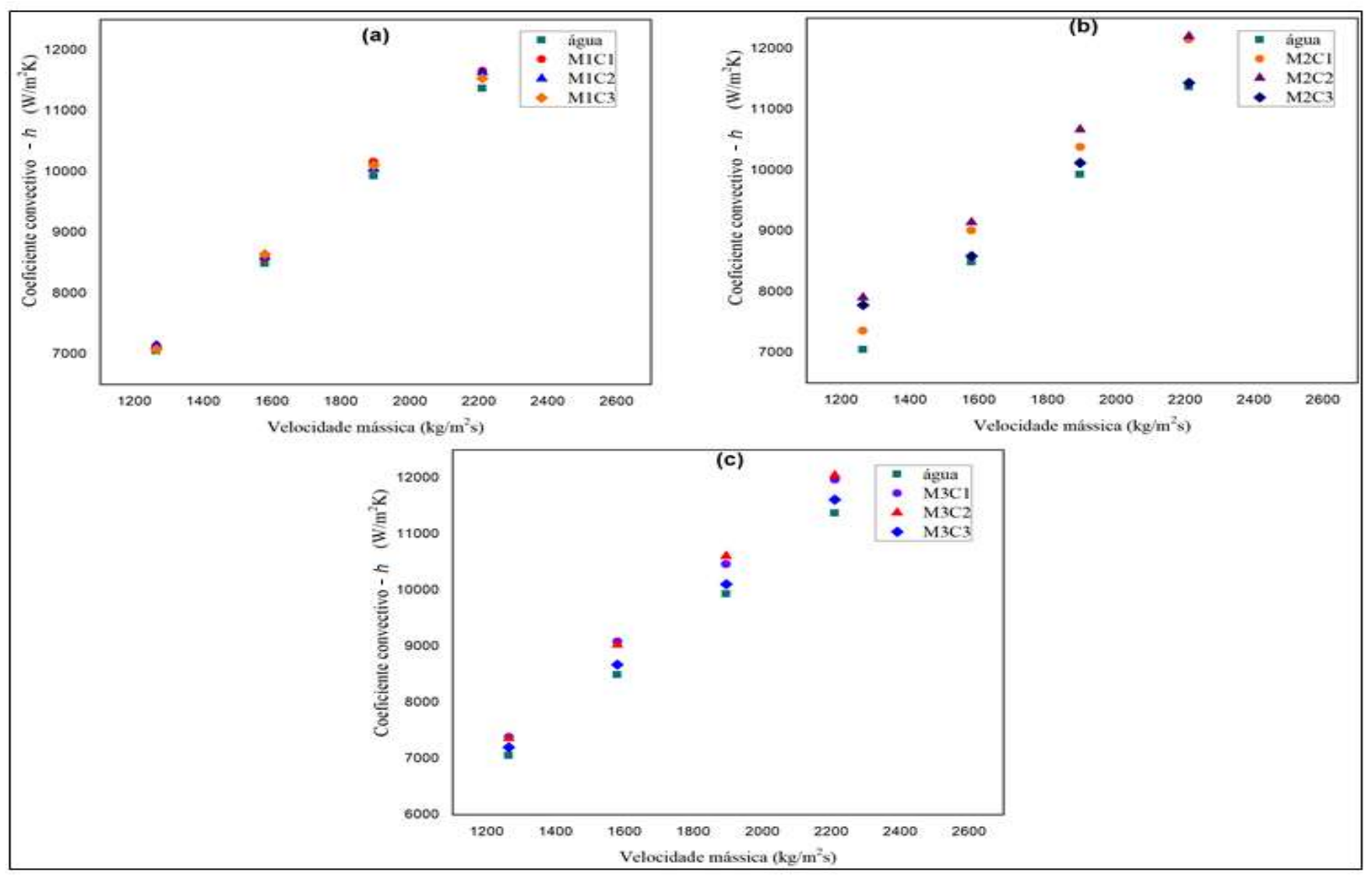

Fonte: Autores.

Considerando as amostras apresentadas na Figura 8a, apenas a amostra com maior concentração de nanopartículas (M1C3) apresentou incremento no coeficiente de transferência de calor em relação ao fluido base. Para as amostras apresentadas na Figura 8b e na Figura 8c, houve aumento no coeficiente de transferência de calor independentemente da concentração nanopartículas na amostra e da vazão mássica. Contudo, como já citado no início desta seção, o método de comparação baseado no número de Reynolds em geral não é o melhor método, em razão de a viscosidade do nanofluido ser superior à do fluido base. 
Figura 8 - Coeficiente convectivo em função do número de Reynolds.

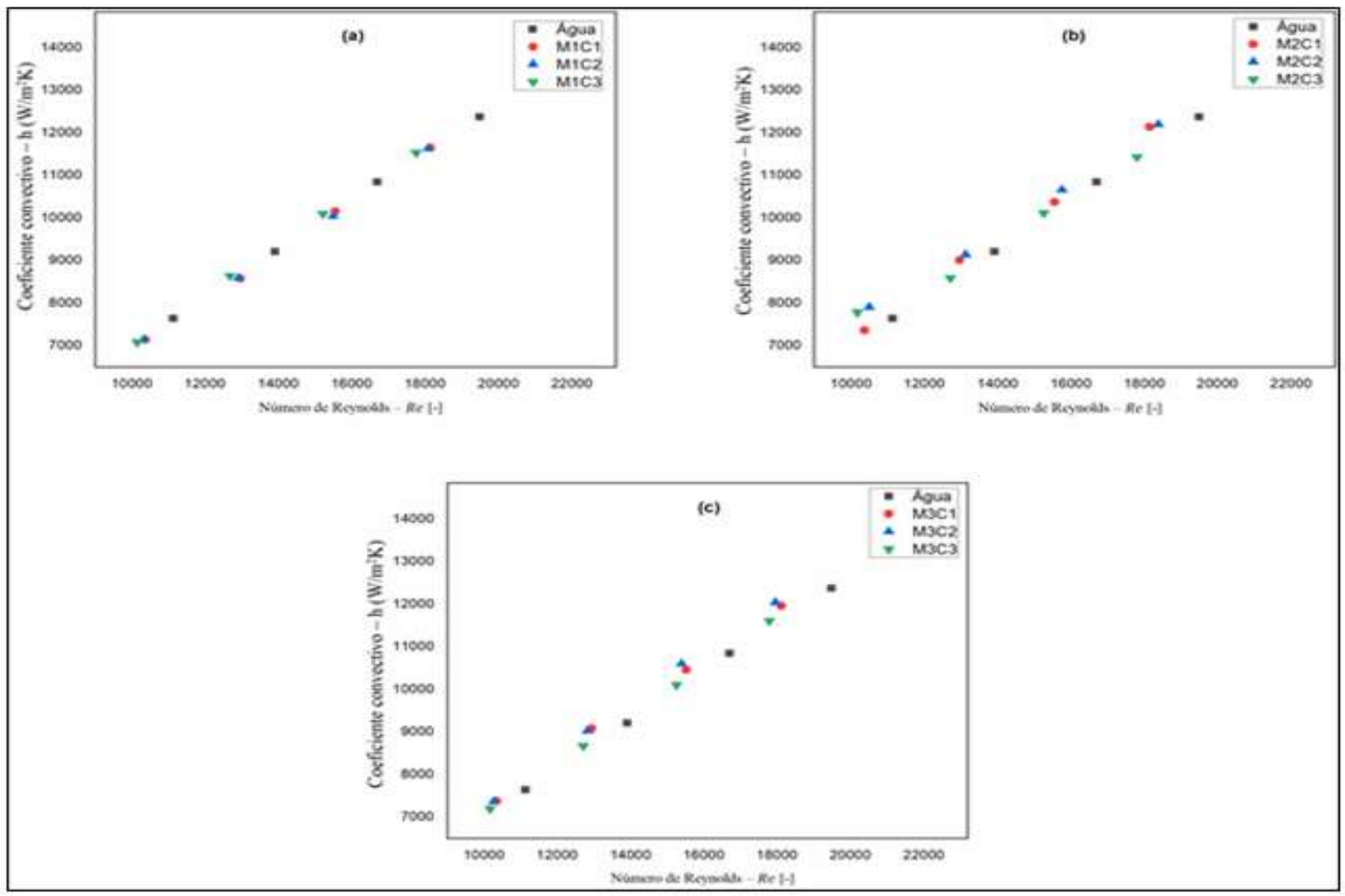

Fonte: Autores.

\subsection{Desempenho termo-hidráulico das amostras de nanofluidos MWCNT/água}

Para que os nanofluidos apresentem benefícios no desempenho térmico de um sistema, é necessário que exista um equilíbrio apropriado entre o aumento na condutividade e na viscosidade, conforme relatam Cárdenas Gómez et al. (2017), O’Hanley et al. (2012) e Prasher et al. (2006).

Segundo Pak e Cho (1998), a comparação baseada no número de Reynolds não é adequada, uma vez que a viscosidade dos nanofluidos é superior à do fluido base. De acordo com (Meyer, Mckrell, \& Grote, 2013), quando são feitas comparações com o mesmo número de Reynolds, qualquer fluido com viscosidade mais elevada irá apresentar maiores coeficientes de transferência de calor, podendo estar sendo avaliado de forma tendenciosa como fluidos refrigerantes promissores.

Para avaliar o desempenho termo-hidráulico das amostras de nanofluidos, foi estabelecida uma comparação entre a potência de bombeamento relativa. Ela é descrita pela razão entre a potência de bombeamento do nanofluido e o fluido base, $\mathrm{W}{ }_{-} \mathrm{nf} /\left(\mathrm{W}_{-} \mathrm{fb}^{\mathrm{f}}\right)$, em função do coeficiente relativo de transferência de calor por convecção. Este é determinado pela razão entre o coeficiente de transferência de calor do nanofluido e do fluido base, h_nfh_fb .

Os testes térmicos e hidráulicos foram realizados simultaneamente e as condições nominais dos testes, descritas na Tabela 2, foram utilizadas para as amostras de nanofluidos e para o fluido base. Os resultados para as amostras M1C1, M1C2 e M1C3 estão representados na Figura 9. Os resultados para as amostras M2C1, M2C2 e M2C3 são apresentados na Figura 10. Na Figura 11 estão representados os resultados para as amostras M3C1, M3C2 e M3C3.

As Figuras são compostas por quatro quadrantes que descrevem a potência de bombeamento relativa, em função do coeficiente convectivo de transferência de calor em coordenadas vetoriais, onde a coordenada $(1,1)$ representa o fluido base 
(água destilada) utilizado na dispersão. O primeiro quadrante $\left(\mathrm{W}_{\mathrm{nf}} /\left(\mathrm{W}_{\mathrm{fb}}\right)>1, \mathrm{~h}_{\mathrm{nf}} / \mathrm{h}_{\mathrm{fb}}>1\right)$ descreve um desempenho termohidráulico esperado para os nanofluidos, onde há um incremento na potência de bombeamento e no coeficiente convectivo de transferência de calor. Vale ressaltar que um desempenho ideal esperado para qualquer nanofluido seria $\left(\mathrm{W}_{\mathrm{nf}} /\left(\mathrm{W}_{\mathrm{fb}}\right)=1, \mathrm{~h}_{\mathrm{nf}} / \mathrm{h}_{\mathrm{fb}}\right.$ >1). O segundo quadrante $\left(\mathrm{W}_{\mathrm{nf}} /\left(\mathrm{W}_{\mathrm{fb}}\right)<1, \mathrm{~h}_{\mathrm{nf}} / \mathrm{h}_{\mathrm{fb}}>1\right)$ representa redução na perda de carga, uma vez que a potência de bombeamento é proporcional a esta grandeza e incremento no coeficiente convectivo de transferência de calor. O terceiro quadrante $\left(\mathrm{W}_{\mathrm{nf}} /\left(\mathrm{W}_{\mathrm{fb}}\right)<1, \mathrm{~h}_{\mathrm{nf}} / \mathrm{h}_{\mathrm{fb}}<1\right)$ representa redução na potência de bombeamento e no coeficiente convectivo. O quarto quadrante, $\left(\mathrm{W}_{\mathrm{nf}} /\left(\mathrm{W}_{\mathrm{fb}}\right)>1, \mathrm{~h}_{\mathrm{nf}} / \mathrm{h}_{\mathrm{fb}}<1\right)$ indica que não há nenhuma vantagem, uma vez que tanto a potência de bombeamento é superior à do fluido base e o coeficiente convectivo de transferência de calor é inferior ao do fluido base, para as mesmas condições nominais de escoamento.

Em todas as amostras de nanofluidos é possível observar uma tendência de aumento na potência de bombeamento com a adição de nanopartículas. Nas amostras com menor grau de funcionalização (Figura 9), os incrementos na potência de bombeamento foram, em média, 1,3\%, 1,7\% e 2,3\%, para as amostras M1C1, M1C2 e M1C3, respectivamente. O maior incremento da potência de bombeamento foi de 2,5\% obtido para a amostra M1C3 na vazão mássica de $(0,0600 \pm 0,0002) \mathrm{kg} / \mathrm{s}$. Já o menor incremento observado foi de 1,1\% para a amostra M1C1 na vazão mássica de $(0,0500 \pm 0,0002) \mathrm{kg} / \mathrm{s}$.

Para as amostras de nanofluidos com grau de funcionalização intermediário (Figura 10) os incrementos na potência de bombeamento, foram em média, 1,1\%, 1,4\% e 2,4\%, para as amostras M2C1, M2C2 e M2C3, respectivamente. O maior incremento da potência de bombeamento ocorreu para a amostra M2C3. Já o menor incremento observado foi de 0,7\% para a amostra M2C1 e ambos ocorreram na vazão mássica de $(0,0500 \pm 0,0002) \mathrm{kg} / \mathrm{s}$.

Os incrementos na potência de bombeamento, para as amostras de nanofluido com maior grau de funcionalização (Figura 11), foram, em média, 1,0\%, 1,2\% e 2,3\%, para as amostras M3C1, M3C2 e M3C3, respectivamente. O maior incremento da potência de bombeamento foi de 2,5\%, para a amostra M3C3, na vazão mássica de $(0,0600 \pm 0,0002) \mathrm{kg} / \mathrm{s}$. Já o menor incremento observado foi de 0,6\% para a amostra M3C1, escoando com vazão mássica de $(0,0500 \pm 0,0002) \mathrm{kg} / \mathrm{s}$.

Figura 9 - Coeficiente de transferência de calor relativo, $\mathrm{h}_{\mathrm{nf}} / \mathrm{h}_{\mathrm{fb}}$, em função da potência de bombeamento relativa, $\mathrm{W}_{\mathrm{nf}} / \mathrm{W}_{\mathrm{fb}}$, para amostras de nanofluidos funcionalizados $-\mathrm{OH} 4 \mathrm{wt} \%$.

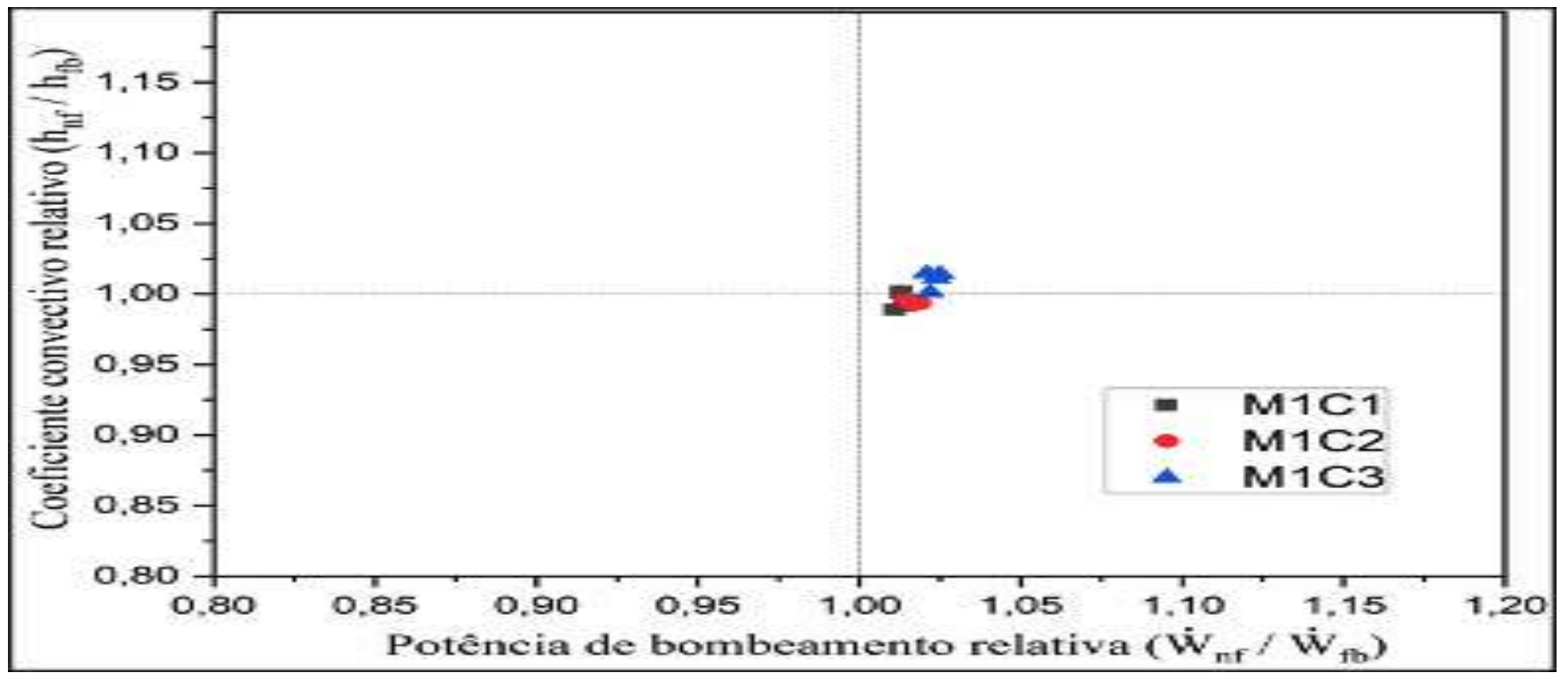

Fonte: Autores. 
Figura 10 - Coeficiente de transferência de calor relativo, $\mathrm{h}_{\mathrm{nf}} / \mathrm{h}_{\mathrm{fb}}$, em função da potência de bombeamento relativa, $\mathrm{W}_{\mathrm{nf}} / \mathrm{W}_{\mathrm{fb}}$ , para amostras de nanofluidos funcionalizados $-\mathrm{OH} 6 \mathrm{wt} \%$.

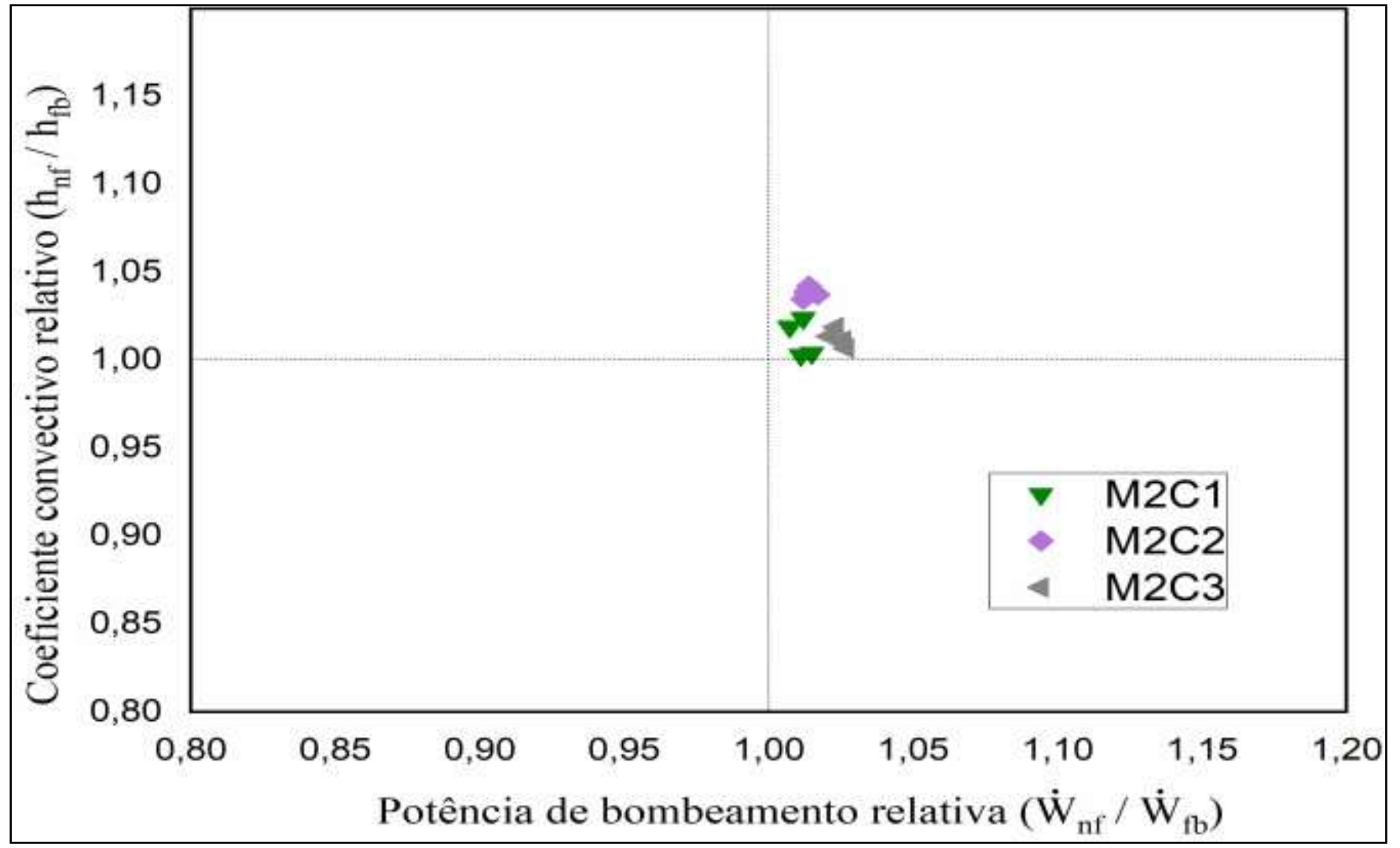

Fonte: Autores.

Figura 11 - Coeficiente de transferência de calor relativo, $\mathrm{h}_{\mathrm{nf}} / \mathrm{h}_{\mathrm{fb}}$, em função da potência de bombeamento relativa, $\mathrm{W}_{\mathrm{nf}} / \mathrm{W}_{\mathrm{fb}}$ , para amostras de nanofluidos funcionalizados $-\mathrm{OH} 9 \mathrm{wt} \%$.

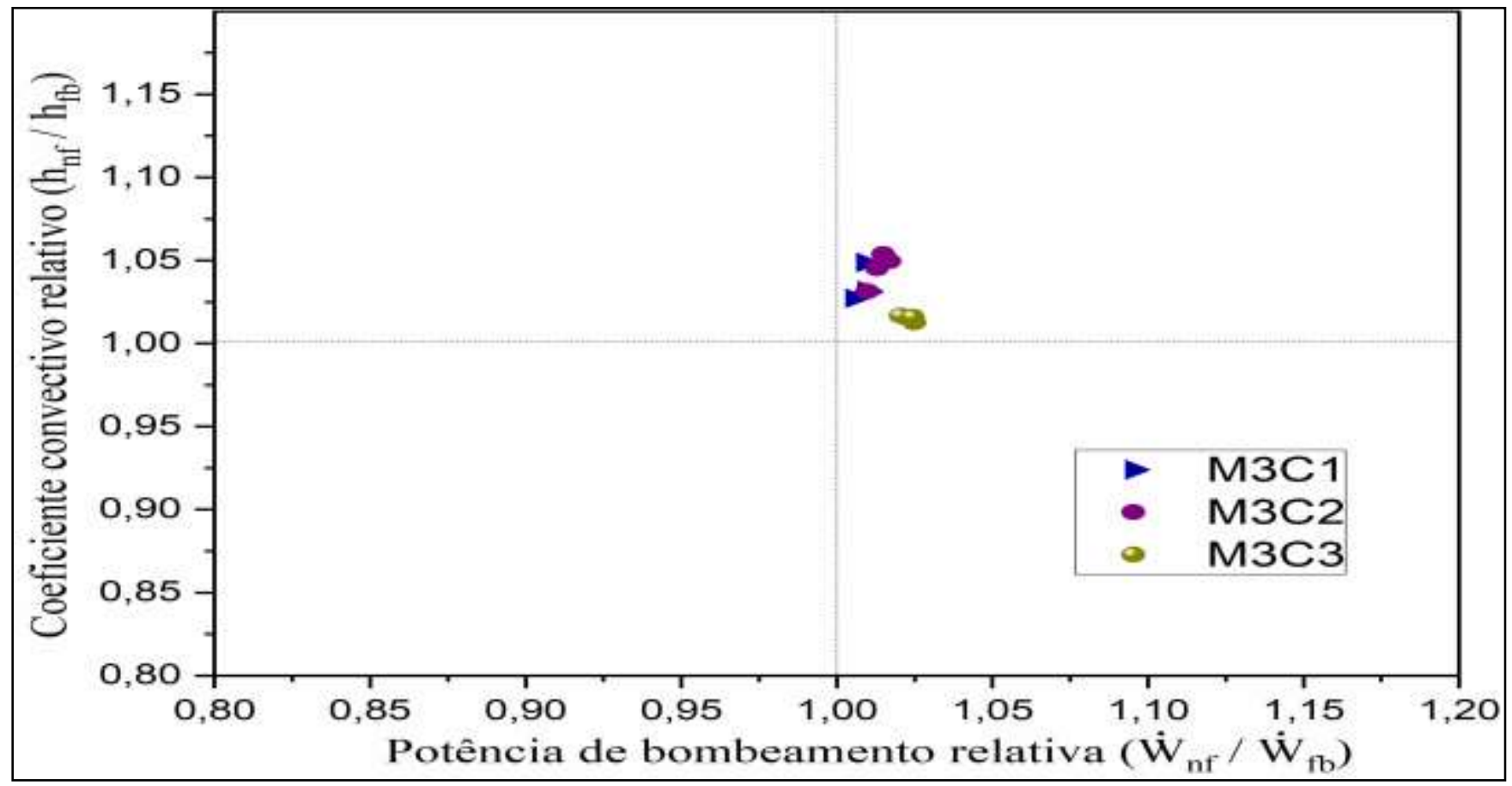

Fonte: Autores. 
De maneira geral não foram observados aumentos significativos na potência de bombeamento das amostras de nanofluidos testadas, devido aos baixos incrementos na queda de pressão. Assim sendo, conforme o critério estabelecido para avaliar o potencial de aplicação dos nanofluidos (MWCNT/água) em função do desempenho termo-hidráulico, a amostra com grau de funcionalização mais elevado e com concentração intermediária de nanopartículas foi a M3C2. Ela apresentou melhor desempenho termo-hidráulico, uma vez que, seus incrementos obtidos para o coeficiente convectivo foram superiores, em média, a $4,5 \%$.

\section{Conclusões}

O coeficiente de transferência de calor foi avaliado em quatro vazões mássicas, variando entre $0,040 \mathrm{~kg} / \mathrm{s}$ até $0,070 \mathrm{~kg} / \mathrm{s}$, com temperatura de entrada igual a $35^{\circ} \mathrm{C}$. O maior valor obtido para o coeficiente convectivo de transferência de calor de $5,4 \%$, nas amostras com maior grau de funcionalização e concentração intermediária de nanopartículas. Essa mesma amostra apresentou melhor desempenho termo-hidráulico, uma vez que os seus incrementos para o coeficiente convectivo foram superiores, em média, a 4,5\%.

Apesar de o desempenho termo-hidráulico não ter sido satisfatório, pode-se concluir que os objetivos gerais da proposta foram cumpridos, pois a presente pesquisa está inserida no empenho para a compreensão do comportamento dos nanofluidos que ainda têm se mostrado contrastantes.

A intenção inicial desse projeto era utilizar o nanofluido MWCNT/água como refrigerante em reatores nucleares à água leve (Oliveira et al., 2019). Entre os motivos para esta escolha está o fato de que os nanotubos de carbono apresentam condutividade térmica bastante elevada e que a funcionalização com os grupos hidroxila - $\mathrm{OH}$, servem para deixar as nanopartículas mais hidrofílicas. Outros tipos de tipos de nanofluidos como por exemplo TiO2/água, foram avaliados teoricamente por Mousavizadeh et al. (2015) e foram recomendados pelos autores para uso em reatores refrigerados à água, que correspondem a grande maioria dos reatores de potência e de pesquisa. No trabalho citado, eles concluíram que ocorreu aumento na condutividade térmica e no coeficiente de transferência de calor do refrigerante.

Com base na pesquisa experimental aqui apresentada, a utilização de nanofluidos MWCNT/água em sistemas de refrigeração de reatores nucleares a princípio não é recomendado. Todavia, para a utilização como fluido de refrigeração de emergência, os nanofluidos MWCNT/água podem se mostrar uma alternativa interessante. Mas é necessário um estudo mais amplo, envolvendo inclusive o custo econômico. É preciso também realizar experimentos em reator nuclear de pesquisa, para se conhecer o comportamento dos nanofluidos na presença de radiação ionizante e sobre a possível mudança na reatividade do núcleo do reator.

Com o objetivo de contribuir para a continuidade de pesquisas nessa área, são apresentadas as seguintes sugestões de trabalhos futuros:

- Avaliar a transferência de calor por convecção em faixas de escoamento mais elevadas.

- Realizar testes experimentais com objetivo de avaliar o desgaste dos equipamentos devido ao escoamento de nanofluidos.

- Analisar o desempenho termo-hidráulico de nanofluidos MWCNT/água composto por nanopartículas funcionalizadas de dimensões distintas das do presente trabalho.

- Avaliar o desempenho termo-hidráulico dos nanofluidos para outras faixas de escoamento e temperaturas.

- Submeter os nanofluidos a um fluxo de nêutrons para se conhecer sua transformação devido à ativação neutrônica, para estudo de seu possível uso em reatores nucleares. 
Research, Society and Development, v. 10, n. 3, e5910313031, 2021

(CC BY 4.0) | ISSN 2525-3409 | DOI: http://dx.doi.org/10.33448/rsd-v10i3.13031

\section{Referências}

Cárdenas Gómez, A. O., Paz Alegrias, J. G., \& Bandarra Filho, E. P. (2017). Experimental analysis of the thermal-hydraulic performance of water based silver and SWCNT nanofluids in single-phase flow. Applied Thermal Engineering. https://doi.org/10.1016/j.applthermaleng.2017.06.090.

Choi, S. U. S. E., \& Eastman, J. A. (1995). Enhancing thermal conductivity of fluids with nanoparticles. In International Mechanical Engineering Congress and Exhibition. San Francisco,CA.

Chupin, A., Hu, L. W., \& Buongiorno, J. (2008). Proceedings of the 2008 International Congress on Advances in Nuclear Power Plants: ICAPP '08: embedded topical meeting, June 8-12, 2008, Anaheim, California: American Nuclear Society.

Gómez, A. O. C. (2019). Avaliação experimental da transferência de calor e perda de pressão de nanofluidos em escoamento monofásico em dutos. Tese.

Incropera, F. P., DeWitt, D. P., Bergman, T. L., \& Lavine, A. S. (2015). Fundamentos de Transferencia de Calor e de Massa. LTC- Livros Técnicos e Científicos Ltda (7th ed.). LTC. https://doi.org/10.1016/j.applthermaleng.2011.03.022.

Kazi, S. N., Duffy, G. G., \& Chen, X. D. (2014). Validation of heat transfer and friction loss data for fibre suspensions in a circular and a coaxial pipe heat exchanger. International Journal of Thermal Sciences. https://doi.org/10.1016/j.ijthermalsci.2014.01.001.

Meyer, J. P. P., Mckrell, T. J. J., \& Grote, K. (2013). The influence of multi-walled carbon nanotubes on single- phase heat transfer and pressure drop characteristics in the transitional flow regime of smooth tubes. International Journal of Heat and Mass Transfer, 58(1-2), 597-609. https://doi.org/10.1016/j.ijheatmasstransfer.2012.11.074.

O’Hanley, H., Buongiorno, J., McKrell, T., \& Hu, L. W. (2012). Measurement and model validation of nanofluid specific heat capacity with differential scanning calorimetry. Advances in Mechanical Engineering. https://doi.org/10.1155/2012/181079.

Pak, B. C., \& Cho, Y. I. (1998). Hydrodynamic and heat transfer study of dispersed fluids with submicron metallic oxide particles. Experimental Heat Transfer, 11(2), 151-170. https://doi.org/10.1080/08916159808946559.

Pereira, A. S. et al. (2018). Metodologia da pesquisa científica. UFSM.

Prasher, R., Song, D., Wang, J., \& Phelan, P. (2006). Measurements of nanofluid viscosity and its implications for thermal applications. Applied Physics Letters. https://doi.org/10.1063/1.2356113.

Sadeghinezhad, E., Mehrali, M. M., Tahan Latibari, S., Mehrali, M. M., Kazi, S. N., Oon, C. S., \& Metselaar, H. S. C. (2014). Experimental investigation of convective heat transfer using graphene nanoplatelet based nanofluids under turbulent flow conditions. Industrial and Engineering Chemistry Research. https://doi.org/10.1021/ie501947u

ScienceDirect. (2018). The Instrumentation Systems and Automation Society (ISA). (1985). ISA-S5.5-1985: Graphic Symbols for Process Displays. American National Standard.

Utomo, A. T., Haghighi, E. B., Zavareh, A. I. T., Ghanbarpourgeravi, M., Poth, H., Khodabandeh, R., \& Pacek, A. W. (2014). The effect of nanoparticles on laminar heat transfer in a horizontal tube. International Journal of Heat and Mass Transfer, 69, 77-91. https://doi.org/10.1016/j.ijheatmasstransfer.2013.10.003 